\title{
Perforated Hepatic Hydatid Cyst into the Peritoneum with Mild Symptoms
}

\author{
A. Dirican B. Unal D. Ozgor T. Piskin C. Aydin \\ F. Sumer C. Kayaalp \\ Department of General Surgery, Inonu University Faculty of Medicine, Malatya, \\ Turkey
}

\author{
Key Words \\ Hydatid disease · Liver · Trauma - Rupture
}

\begin{abstract}
Rupture into the abdominal cavity is a rare but serious complication of hydatid disease that necessitates emergency surgical intervention. We present herein a case with mild abdominal symptoms due to hydatid cyst rupture into the peritoneum after trauma. A 24-year-old man was admitted to the emergency room with mild abdominal pain. His symptoms had started after a fall four days earlier. Ultrasonography and computed tomography showed cystic lesions in the liver and peritoneum with intraabdominal free fluid. He was treated surgically with partial cystectomy and falciformoplasty.

Postoperative albendazole therapy was given for two months. There was not recurrence four months postoperatively at control computed tomography.
\end{abstract}

\section{Introduction}

Hydatid disease is a parasitic infestation caused by Echinococcus granulosus and less frequently by Echinococcus multilocularis. Humans contract the disease through enteral exposure and become accidental intermediate hosts [1]. Hydatidosis is endemic in the Mediterranean region including Turkey [2]. In humans $50-75 \%$ of hydatid cysts occur in the liver [3]. Although hydatid liver disease may be asymptomatic for many years, one common complication of hydatid disease is perforation of the cyst into the peritoneal cavity after trauma or spontaneously, causing mild to fatal complications such as abdominal pain, urticaria, anaphylaxis and sudden death [4]. In this study, we present a case of hepatic hydatid cyst rupture into the peritoneum after trauma with mild abdominal symptoms operated four days after perforation. 


\section{Case Report}

A 24-year-old man was admitted to the emergency department with mild abdominal pain, nausea and vomiting. The abdominal pain had started after a fall four days earlier. He had taken analgesics. His vital signs were normal. Abdominal palpation revealed mild tenderness. There was not abdominal rigidity or tenderness. Labratory investigations were normal except for mild leukocytosis (WBC: $12,000 / \mathrm{ml}$ ). Abdominal ultrasound (US) showed a large amount of free fluid in the abdominal cavity and cystic lesions in the liver. Computed tomography (CT) showed four cysts in the liver and one of that cyst's border was incomplete (fig. 1, fig. 2).

The patient underwent emergency surgery and the abdomen was exposed through a midline insicion. Approximately 2,000 $\mathrm{ml}$ clear fluid was aspirated from the intraperitoneal space. There was a ruptured cyst $11 \mathrm{~cm}$ in diameter near the surface of the right liver at the fourth and sixth segment. There were daughter vesicles encapsulated by omentum. The germinative membrane and the daughter vesicles were removed.

At exploration of the abdomen there were another six hydatid cysts in the liver. The perforated cysts cavity and abdomen were irrigated with hypertonic saline $(3 \% \mathrm{NaCl})$ and then with isotonic saline. The hypertonic saline was injected into the other six cysts followed by a $10 \mathrm{~min}$ pause. Partial pericystectomy and drainage were performed. The perforated cyst was treated with partial pericystectomy and falciformoplasty. Saline test revealed no connection between the cysts and the bile ducts. A JacksonPratt drain was inserted into the subhepatic and the rectovesical space.

The patient was discharged from the hospital on the fifth postoperative day without any complication. Postoperative albendazole therapy was given for two months. There was not recurrence in control CT four months postoperatively.

\section{Discussion}

Infection with echonococcal organisms is the most common cause of liver cysts worldwide [3]. Hydatid cysts of liver have an internal cellular layer (germinal layer) and an outer acellular layer (laminated layer). As the cyst expands gradually, a granulomatous host reaction followed by a fibrous reaction forms a connective tissue layer, which is called pericyst [5]. The pericyst is a strong layer.

Hydatid cysts of the liver are asyptomatic or cause mild right upper abdominal pain until complications occur. Perforation of the cyst into the peritoneum is one of them. Major or minor blunt abdominal trauma can cause rupture of hydatid cysts. Spontaneous perforation of hydatid cysts has been reported as well [6]. Various incidence rates of rupture have been reported, being $7.8 \%$ in one series [7]. The main predisposing factors for cyst perforation are young age and superficial localization [7]. Other risk factors are large cyst diameter and high intracystic pressure [8].

The clinical signs and symptoms of cyst rupture are not always severe, but all patients suffer from abdominal pain [8]. Peritoneal signs and symptoms may develop earlier and can be more severe if bile leakage occurs or if the cyst is infected. There was no connection between the cysts and the bile ducts in our case. In the study of Patel and Butt, $76 \%$ of patients with ruptured hydatid cyst had abdominal pain [9]. The severe clinical presentation and infrequency of hydatid cyst perforation have been held partially responsible for the misdiagnosis by the surgeon. However, as in our case the patient may sometimes be misdiagnosed because of mild or no abdominal pain.

Anaphylaxis and even sudden death have also been reported in patients with ruptured hydatid cyst, but this is not as common as once thought [8]. Nearly all parasitic infections can cause eosinophilia and allergic symptoms. It is not known in which patients and circumstances these reactions occur. There was no sign of allergic reaction or anaphylaxis in our patient. All patients in the literature were operated within $24 \mathrm{~h}$ after perforation. In 


\begin{tabular}{r|l|l|l} 
Case Reports $/ \mathrm{h}$ & $\begin{array}{l}\text { Case Rep Gastroenterol 2008;2:439-443 } \\
\text { D0I: 10.1159/000161564 }\end{array}$ & Published online: November 18, 2008 & $\begin{array}{l}\text { O 2008 S. Karger AG, Basel } \\
\text { ISSN 1662-0631 } \\
\text { www.karger.com/crg }\end{array}$ \\
\hline
\end{tabular}

contrast, our patient came to the emergency department four days after cyst perforation. He had mild abdominal pain, nausea and vomiting.

US is widely used for the diagnosis of hydatid cyst and has acceptable specificity and sensitivity [10]. It is also noninvasive. The US findings of hydatid cyst rupture include detection of the cyst and of free intraperitoneal fluid. CT is another choice to detect cyst rupture and is very effective. It is useful for determining the exact site of the cyst and its features [10]. CT can shows the free intraabdominal fluid. Our patient's cyst rupture was diagnosed using US and CT. We saw only four hydatid liver cysts on CT, but there were seven at laparotomy.

The treatment of perforated hydatid cysts is surgery. Surgical methods used in the treatment of hydatid disease are radical (pericystectomy and hepatic resection) and conservative procedures (unroofing associated with various procedures for the management of the residual cavity) [11]. Each method has advantages and disadvantages. We prefer partial pericystectomy and falciformoplasty for the treatment of perforated cysts. Omentoplasty is an effective technique for managing the residual cavity after partial cystectomy. But omentum was short in our case. Therefore we used falciform ligament as a flap instead of omentum as described by Ozmen et al. previously [12].

In conclusion, acute abdominal findings of defense, rebound, and tenderness may not be present at rupture of hydatid cyst of the liver into the peritoneum. US and CT are effective in diagnosing this rare condition.

Fig. 1. CT of perforated hepatic hydatid cyst into peritoneum.

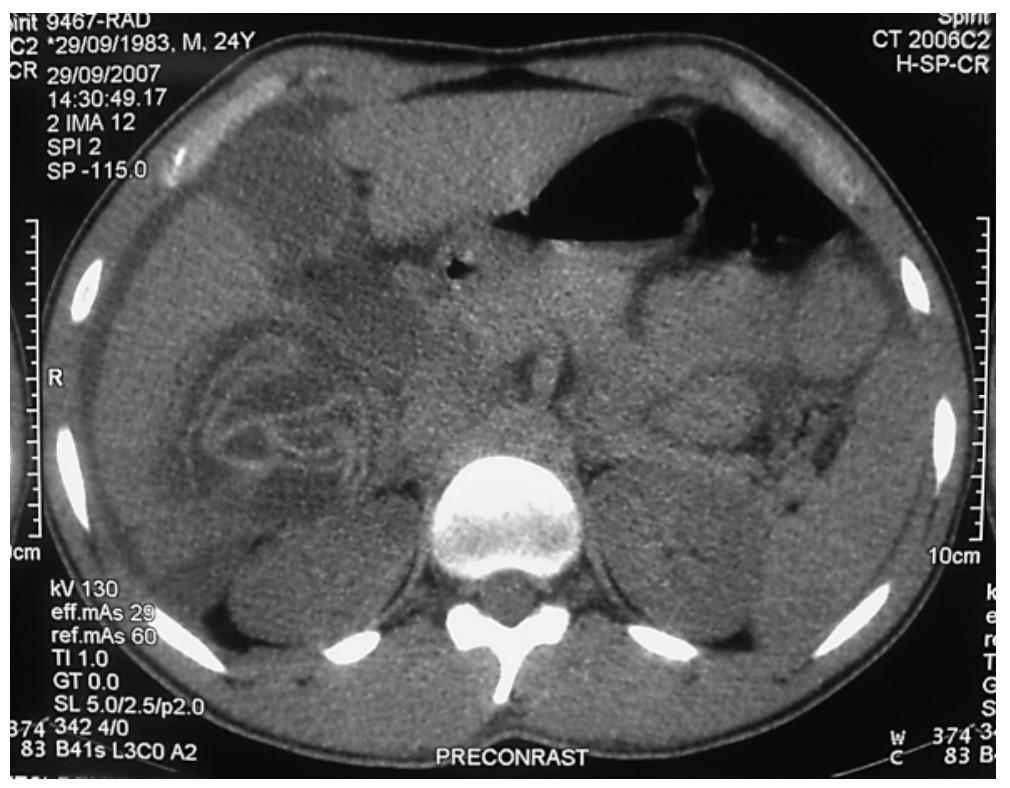



\begin{tabular}{l|l} 
Case Repports $/$ n & Case Rep Gastroenterol 2008;2:439-443 \\
DOI: 10.1159/000161564
\end{tabular}

Fig. 2. CT of free fluid into peritoneum and incomplete border of hepatic hydatid cyst.

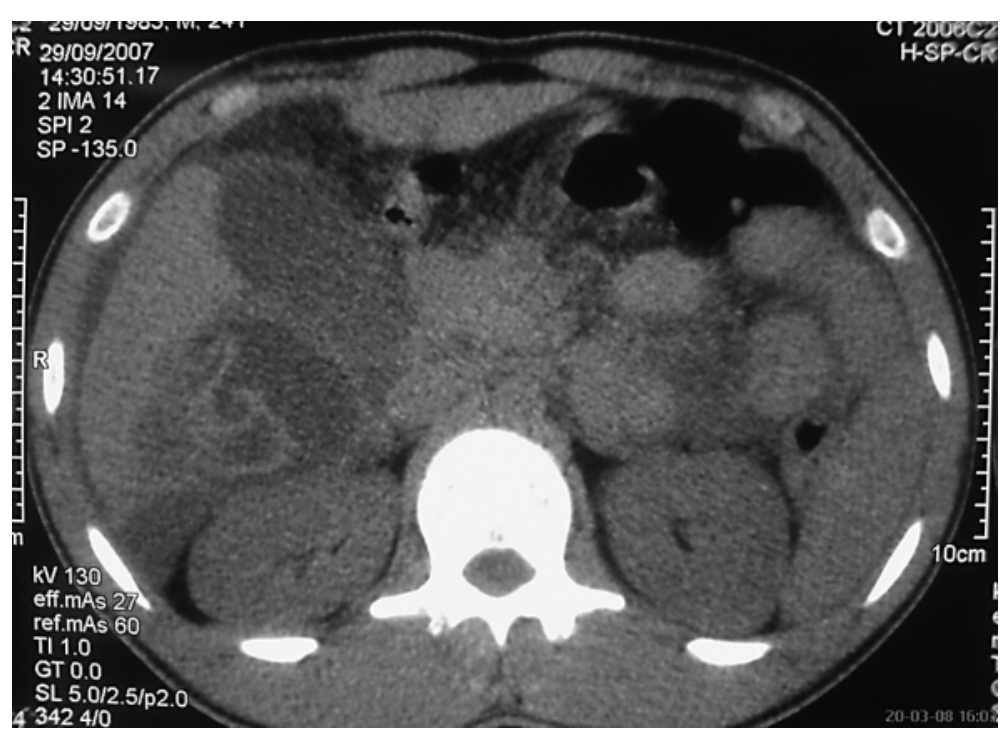




\section{References}

1 Kayaalp C: Hydatid cyst of the liver; in Blumgart LH, Belghiti RJ, DeMatteo RP, Chapman WC, Büchler MW, Hann LE, D’Angleca M (eds): Surgery of the Liver, Biliary Tract, and Pancreas, ed 4. Philadelphia, Saunders Elsevier, 2007, pp 952970.

2 Sayek I, Yalın R, Sanaç Y: Surgical treatment of hydatid disease of the liver. Arch Surg 1980;115:847-850.

3 Barnes SA, Lillemoe KD: Liver abscess and hydatid cyst disease; in Zinner MJ, Schwartz SI, Ellis H (eds): Maingot's Abdominal Operations, ed 10. Stamford, Appleton and Lange, 1997, pp 1513-1545.

-4 Derici H, Tansug T, Reyhan E, Bozdag AD, Nazli O: Acute intraperitoneal rupture of hydatid cysts. World J Surg 2006;30:1879-1883.

5 Eckert J, Deplazes P: Biological, epidemiological and clinical aspect of echonococcosis, a zoonosis of increasing concern. Clin Microbiol Rev 2004; 17:107-135.

6 Karakaya K: Spontaneus rupture of a hepatic hydatid cyst into the peritoneum causing mild abdominal pain: case report. World J Gastroenterol 2007;13:806808.

-7 Akcan A, Akyıldız H, Artis T, Ozturk A, Deneme MA, Ok E, Sözüer E: Peritoneal perforation of liver hydatid cysts: clinical presentation, predisposing factors, and surgical outcome. World J Surg 2007;31:1284-1291.

8 Ozturk G, Aydınlı B, Yıldırgam MI, et al: Posttraumatic free intraperitoneal rupture of liver cystic echinococcosis: a case series and review of literature. Am J Surg 2007;194:313-316.

-9 Patel SS, Butt AA: Inadvertent rupture of an echinococcal cyst: case report and report of literature. Am J Med 2004;327:268-271.

10 Kurt N, Oncel M: Spontaneus and traumatic intraperitoneal perforations of hepatic hydatid cysts: a case series. J Gastrointest Surg 2003;7:635-645.

-11 Dziri C, Haouet K, Fingerhut A: Treatment of hydatid cyst of the liver: where is the evidence? World J Surg 2004;28:731-736.

12 Ozmen MM, Coskun F, Ziraman I: Falciform ligament in the management of the residual cavity for liver hydatidosis: a new surgical technique. World J Surg 2006;30:1722-1728. 